\title{
5G Teknolojisi için Çift Bantlı(28/38 GHz) Dikdörtgen Mikroşerit Anten Tasarımı Araştırma Makalesi/ Research Article
}

\author{
Murat DEMIRCI, (D) Seda ERMIŞ \\ Elektrik Elektronik Mühendisliği, Osmaniye Korkut Ata Üniversitesi, Osmaniye, Türkiye \\ muratdemirci307@gmail.com, sedaermis@osmaniye.edu.tr \\ (Geliş/Received:19.10.2020; Kabul/Accepted:30.03.2021) \\ DOI: $10.17671 /$ gazibtd. 813103
}

\begin{abstract}
Özet-Düşük atmosferik zayıflamaları nedeniyle $28 \mathrm{GHz}$ ve $38 \mathrm{GHz}$ frekansları $5 \mathrm{G}$ teknolojisi için önemli iki frekans bantları olarak bu çalışmanın temelini oluşturmuştur. Farklı besleme yöntemleri ve bant genişliği arttırma tekniklerinin kullanıldığı bu çalı̧̧mada dikdörtgen mikroşerit antenlerin HFSS programı ortamında benzetim çalışmaları yapılmıştır. Dikdörtgen yama üzerine açılan yarıklar ile çift bantta rezonansa giren dikdörtgen mikroşerit anten farklı besleme yöntemi ve ilave teknikler ile bant genişliği arttırılmıştır. 28 ve $38 \mathrm{GHz}$ frekanslarında çalışan dikdörtgen mikroşerit antenin en yüksek bant genişliği, toprak yüzeyinin bozulmuş olduğu ve iki alttaşa sahip yakınlık kuplajlı besleme yapısı ile elde edilmiştir. $28 \mathrm{GHz}$ ve $38 \mathrm{GHz}$ frekansları için elde edilen bant genişlikleri sırasıyla $4.79 \mathrm{GHz}$ ve $5.67 \mathrm{GHz}$ olarak HFSS benzetim programıyla hesaplanmıştır. Dikdörtgen mikroşerit antenin çift frekans için kazanç değerleri ise sırasıyla 8.16 $\mathrm{dB}$ ve $7.06 \mathrm{~dB}$ olarak bulunmuştur.
\end{abstract}

\section{Dual Band (28/38 GHz) Rectangular Microstrip Antenna Design For 5G Technology}

\begin{abstract}
GHz}$ and $38 \mathrm{GHz}$ frequencies due to low atmospheric attenuation formed the basis of this study as two important frequency bands for $5 \mathrm{G}$ technology. In this study, in which different feeding methods and bandwidth increasing techniques are used, simulation studies of rectangular microstrip antennas in the environment of the HFSS program are made. The rectangular microstrip antenna resonating in dual band with slots opened on the rectangular patch, the bandwidth has been increased with different feeding method and additional techniques. The highest bandwidth of the rectangular microstrip antenna operating at frequencies of $28 \mathrm{GHz}$ and $38 \mathrm{GHz}$ was obtained with a proximity coupled feed structure with two substrates where defected ground structure. The bandwidths obtained for $28 \mathrm{GHz}$ and $38 \mathrm{GHz}$ frequencies were calculated as $4.79 \mathrm{GHz}$ and $5.67 \mathrm{GHz}$ respectively, with the HFSS simulation program. The gain values of the rectangular microstrip antenna for dual frequency were found to be $8.16 \mathrm{~dB}$ and $7.06 \mathrm{~dB}$ respectively.
\end{abstract}

Keywords - 5G, microstrip antenna, $28 \mathrm{GHz}, 38 \mathrm{GHz}$, defected ground structure

\section{GIRIŞ (INTRODUCTION)}

Akıllı cihazların giderek yaygınlaşması, yeni teknolojik cihazların tanıtımı ile birlikte ortaya çıkan multimedya uygulamaları ve kablosuz veri talebindeki artış mevcut hücresel ağlar üzerinde önemli bir yük oluşturmaktadır. $1 \mathrm{G}, 2 \mathrm{G}, 3 \mathrm{G}$ ve $4 \mathrm{G}$ mobil ağlarından sonra yeni bir küresel haberleşme standardı olan 5.Nesil mobil haberleşme teknolojisinin bu ihtiyaçları karşılamak için devrim niteliğinde bir gelişme göstermesi beklenmektedir [1]. 5G, makineler, nesneler ve cihazlar da dâhil olmak üzere neredeyse her şeyi birbirine bağlamak için tasarlanmış yeni bir ăg türü olarak tanımlanmaktadır [2]. 5G kablosuz haberleşme teknolojisi, daha yüksek veri hızı, ultra düşük gecikme süresi, daha fazla güvenirlik, büyük ağ kapasitesi ve daha fazla kullanıcıya daha düzenli bir kullanıcı deneyimi sunmayı hedeflemektedir [3]. Düzenleyici 
kuruluşların kullanıma sunduğu yeni 5G bantları, ağların nasıl dağıtılacağını da belirlemektedir. İlk olarak $5 \mathrm{G}$ orta bantlar (örneğin $3.5 \mathrm{GHz}$ ) ve milimetre dalga bantları (24$100 \mathrm{GHz}$ ), ek kapasitenin ihtiyaç duyulduğu kentsel erişim noktalarındaki yoğun $5 \mathrm{G}$ küçük hücre ağları için kullanılacaktır [4]. Şekil 1'de 5G için öncü bantların ülkelere göre değişkenlik durumları gösterilmektedir. ABD, Japonya, Güney Kore ve bazı Avrupa ülkelerinde 28 $\mathrm{GHz}$ bandının yaygın olarak test çalışmalarının yapıldığ görülmektedir [5].

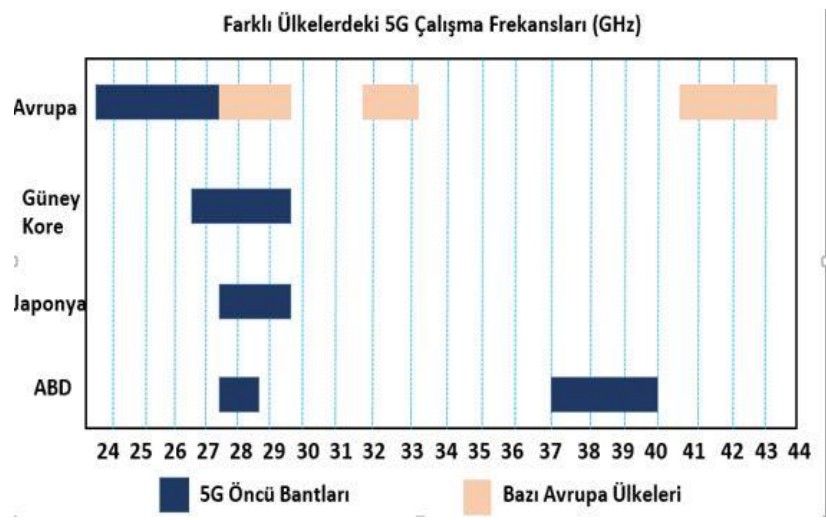

Şekil 1. Farklı ülkelerdeki 5G çalışma frekansları (5G operating frequencies in different countries)

ABD, $28 \mathrm{GHz}$ ve $38 \mathrm{GHz}$ spektrumlarını lisanslamıştır. Aynı şekilde Japonya ve Güney Kore'de $28 \mathrm{GHz}$ için frekans tahsis etmiştir. Avrupa ülkeleri ise $26 \mathrm{GHz}$ ve 41 $43 \mathrm{GHz}$ frekanslarında çalışmalarına devam etmektedir. $28 \mathrm{GHz}, 38 \mathrm{GHz}, 71-76 \mathrm{GHz}$ ve $81-86 \mathrm{GHz}$ bantlar1 5G yerel alanı dağıtmak için mükemmel adaylar olarak görülmektedir [5]. Bu bantlar birçok ülkede lisanslı olarak mevcuttur. Milimetre dalga bandı için atmosferik emilim ve yağmur zayıflaması dalga frekanslarını $200 \mathrm{~m}$ mertebesindeki hücre boyutları için tolere etmektedir. 30 GHz'de atmosferik kayıp $<0.1 \mathrm{~dB} / \mathrm{km}$ oranında soğurulma olmaktadır. 28 ve $38 \mathrm{GHz}$ ' de $0.08 \mathrm{~dB} / \mathrm{km}$ ve 70 ile $90 \mathrm{GHz}$ arasındaki frekanslarda yaklaşı $0.3 \mathrm{~dB} / \mathrm{km}$ 'lik bir zayiflama mevcuttur [6].

5G haberleşme teknolojisine uygun anten tasarımlarının belirtilen frekans bantlarında daha yüksek verim ve bant genişliği, daha düşük maliyet ve hassasiyete sahip olmaları beklenmektedir. Bu anlamda küçük boyutlu, düşük güçte çalışan, kolay üretilebilen ve milimetre dalga bandında iyi performansa sahip mikroşerit yama antenler güçlü bir aday olarak karşımıza çıkmaktadır. Baz istasyonları, cep telefonları ve diğer mobil cihazlar için de bu antenlerin oldukça kullanışlı olduğu bilinmektedir. Ayrıca, mikroşerit antenler kazanç ve verimlilik açısından yüksek frekanslarda çalışılan 5G teknolojisi için yol kaybını tolere edebilmektedir. Bunun yanında, mikroşerit yama antenlerin en büyük dezavantajı ise dar bant genişliğine sahip olmalarıdır. Antenlerde bant genişliği ihtiyacı günümüz kablosuz uygulamaların çeşitliliği ile doğru orantılı olarak artmaktadır. Tek bir antenin çok bantlı iletişimde, alıcı-verici haberleşmesinde ve birden fazla uygulamada performans göstermesi beklenmektedir. $\mathrm{Bu}$ çalışmada $28 \mathrm{GHz}$ ve $38 \mathrm{GHz}$ frekansları için geniş bantta yayın yapan mikroşerit anten tasarımları yapılması hedeflenmiştir.

Literatüre bakıldığında yeni bir teknoloji olan $5 \mathrm{G}$ için anten tasarım çalışmalarının birkaç yıl öncesine dayandığ görülmektedir. 2015 yılında, Osama M. Haraz ve arkadaşları, yakınlık kuplaj besleme yöntemini kullanarak 5G mobil iletişimi için mikroşerit anten tasarımı yapmışlardır. $28 \mathrm{GHz}$ frekansında yaklaşık $8 \mathrm{GHz}, 38$ $\mathrm{GHz}$ frekansında ise $6 \mathrm{GHz}$ 'lik bant genişliğine sahip mikroşerit anten tasarımları bu çalışmada rapor edilmiştir [7]. Benzer şekilde, 2016 y1lında da Mohamed Mamdouh M. Ali ve çalışma arkadaşları, yakınlık kuplaj besleme yöntemi kullanılarak $28 / 38 \mathrm{GHz}$ frekanslarında rezonansa giren mikroşerit yama anten tasarımı yapmışlardır. Dairesel yama şekilli mikroşerit anten kullanılan tasarımda düşük dielektrik sabitine $\varepsilon_{r}=2.2$ sahip olan Rogers RT Duroid 5880 kullanılmış, 28 ve 38 GHz'de yaklaşık olarak sırasıyla 5.5 ve $6 \mathrm{GHz}$ bant genişliği elde etmişlerdir [8]. Yapılan bu ve benzer çalışmaları bant genişliğini arttırma teknikleri eklenerek yapılan mikroşerit anten tasarımlar takip etmiştir. Farklı besleme teknikleri ve alttaş materyalleri kullanılarak ve toprak yüzeyinde yarıklar açılarak yapılan tasarımlarda, antenlerin geri dönüş kaybı, kazanç ve bant genişliği karşılaştırılmıştır [9-14].

Bu çalışmada $5 \mathrm{G}$ teknolojisi için uygun $28 \mathrm{GHz}$ ve $38 \mathrm{GHz}$ frekanslarında yayılım yapan bant genişliği ve kazancı yüksek, çift bant dikdörtgen mikroşerit anten tasarımı amaçlanmıştır. Geleneksel dikdörtgen mikroşerit anten tasarımından farklı olarak yı̆̆ın yama, bozulmuş toprak yüzeyi gibi yöntemler uygulanmış ve farklı besleme tipleri denenerek bant genişliği geri dönüşüm kaybı ve kazanç parametreleri literatürdeki sonuçlar ile karşılaştırılmıştır.

\section{DİKDÖRTGEN MİKROŞERITT ANTEN (DMŞA) İÇIN İLETIM HATTI MODELİ (TRANSMISSION LINE MODEL FOR RECTANGULAR MICCROSTRIP ANTENNA)}

Mikroşerit antenler hafiflik, küçük hacim ve düşük maliyet gibi avantajlarından dolayı yaygın olarak kullanılan anten türüdür. En temel formda bir mikroşerit anten Şekil 2'de gösterildiği gibi toprak düzlemi, dielektrik tabaka ve 1şıma yapan yamadan meydana gelmektedir [15].

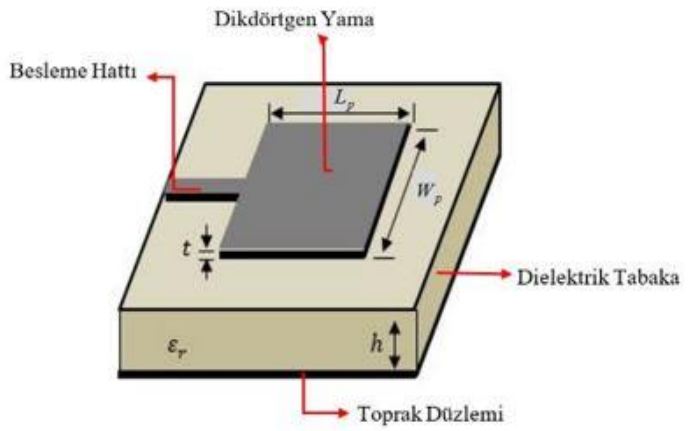

Şekil 2. Dikdörtgen mikroşerit anten (Rectangular microstrip antenna)

Kullanım alanı bakımından en yaygın yama geometrisi dikdörtgen şekle sahip yamalardır. Işıma yapan yamanın 
genişliği $W_{p}$, uzunluğu $L_{p}$, kullanılan alttaşın (dielektrik tabaka) dielektrik sabiti $\varepsilon_{r}$ ve kalınlığ 1 ise $h$ olarak Şekil 2 'de gösterilmiştir. İyi bir anten performansı için alttaşın dielektrik sabitinin $2.2 \leq \varepsilon_{r} \leq 12$ aralığının alt ucunda olan kalın tabanlı malzemeler tercih edilmektedir. Düşük dielektrik sabitine sahip kalın malzemeler daha iyi radyasyon verimliliği ve daha yüksek bant genişliği sağlamaktadır. Matematiksel modelde, ilk olarak mikroşerit yama genişliği $W_{p}$ ve uzunluğu $L_{p}$ değerleri antenin çalışma frekansı ve belirlenen dielektrik sabitine bağlı olarak bulunur [15-16].

$W_{p}=\frac{1}{2 f_{r} \sqrt{\mu_{o} \varepsilon_{o}}} \sqrt{\frac{2}{\varepsilon_{r}+1}}=\frac{\vartheta_{o}}{2 f_{r}} \sqrt{\frac{2}{\varepsilon_{r}+1}}$

Burada, $\vartheta_{O}=c=3 \times 10^{8} \mathrm{~m} / \mathrm{sn}$; Boş uzaydaki ışık hızı), $\mu_{o}=4 \pi \times 10^{-7} \mathrm{~Wb} / \mathrm{A} \mu ; \quad$ Boş uzaydaki manyetik geçirgenlik ve $\varepsilon_{o}=8.85 \times 10^{-12} \mathrm{~F} / \mathrm{m}$; Boş uzaydaki dielektrik sabitidir.

Mikroşerit antenin üst yüzeyinde yama, alt yüzeyde dielektrik tabaka ve hava bulunduğundan dolayı, homojen olmayan bir yapıya sahiptir. Bu yapı elektriksel geçirgenlik değerinin değişmesine neden olur. Yeni durum için etkin dielektrik sabiti (effective dielectric constant) $\varepsilon_{\text {reff }}$, denklem (2) ile hesaplanır [15-16].

$\frac{W_{p}}{h}>1$

$\varepsilon_{\text {reff }}=\frac{\varepsilon_{r}+1}{2}+\frac{\varepsilon_{r}-1}{2}\left[1+12 \frac{h}{W_{p}}\right]^{-\frac{1}{2}}$

Işıma yapan elektrik alan, yamayı fiziksel olarak olduğundan daha büyük bir elektriksel boyuta taşır. $L_{e f f}$ yamanın elektriksel uzunluğu ve $\Delta L$ yama etrafında saçaklanan alan denklem (4) ve (5) ile hesaplanır.

$\Delta L=\frac{0.412 h\left(\varepsilon_{\text {reff }}+0.3\right)\left(\frac{W_{p}}{h}+0.264\right)}{\left(\varepsilon_{\text {reff }}-0.258\right)\left(\frac{W_{p}}{h}+0.8\right)}$

$L_{e f f}=\frac{1}{2 f_{r} \sqrt{\varepsilon_{\text {reff }}} \sqrt{\mu_{o} \varepsilon_{o}}}$

Yamanın gerçek uzunluğu $L_{p}$ ise denklem (6) ile hesaplanır.

$L_{p}=L_{e f f}-2 \Delta L=\frac{1}{2 f_{r} \sqrt{\varepsilon_{r e f f}} \sqrt{\mu_{0} \varepsilon_{o}}}-2 \Delta L$

\section{3. ÇIFT BANTLI (28/38 GHz) DMŞA TASARIMI (DUAL BAND 28/38 GHz RMA DESIGN)}

Öncelikli olarak $28 \mathrm{GHz}$ frekansı için DMŞA iletim hattı modeli kullanılarak anten boyutları hesaplanmıştır. Hesaplanan değerler HFSS 13.0 benzetim programı kullanılarak optimize edilmiştir. Besleme tipi olarak içerden temassız mikroşerit besleme hattı kullanılmıştır. Empedans uyumlandırması boşluk ve mikroşerit besleme hattının genişliği ayarlanarak yapılmıştır. Daha sonra ise $38 \mathrm{GHz}$ 'de ikinci bir frekansta antenin rezonansa girmesi için mikroşerit yama üzerinde simetrik iki boşluk açılmıştır. Yama üzerinde oluşturulan bu yarıklar akım dağılımını bozarak ikinci bir frekans modunu tetiklemektedir. Yama üzerindeki yüzey akımlarının yoğun olduğu bölgelere yarık açılarak yüzey akımlarının yolunun uzaması sağlanabilir. Böylece 1şıma paterni değiştirilerek ikinci frekansın oluşması sağlanmaktadır.

\section{1. Çift Bantlı (28/38 GHz) İçeriden Temassız Beslenen DMŞA (Dual Band 28/38 GHz Non-Contacting Insert Feed RMA)}

Şekil 3'de çift bantta yayılım yapan içerden temassız mikroşerit hat ile beslenmiş DMŞA geometrisi gösterilmiştir. Anten üzerinde açılan boşlukların boyutları ve yama üzerindeki konumları ikinci frekansı değiştirmektedir. Boşluklar antenin sağ ve sol kenarlarından simetrik olarak açılmıştır. Yamanın kenarlarından yamanın merkezine doğru iki çentik eş mesafelerle $\left(d_{1}=d_{2}\right)$ ötelenmiştir. Her adımda çentiklerin uzunluğu ve genişliği de değiştirilerek anten performansının (geri dönüş kaybı ve bant genişliği) en iyi olduğu değerler bulunmuştur.

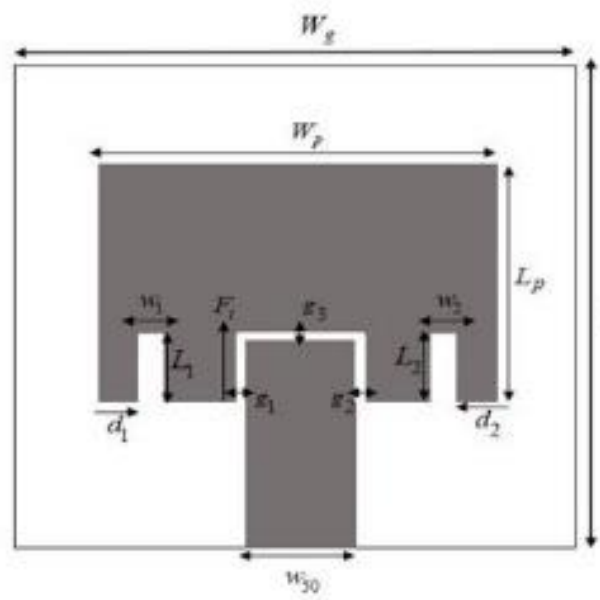

Şekil 3. Simetrik çubuk yarıklı DMŞA (Symmetrical rod slot RMA)

Dielektrik malzeme olarak RT Duroid 5880 kullanılmıştır. Malzemenin dielektrik sabiti $\varepsilon_{r}=2.2$ ve kalınlığ $\mathrm{h}=0.508$ mm'dir. Simülasyonu yapılan anten parametreleri Tablo 1 'de özetlenmiştir. 
Tablo 1. Simetrik çubuk yarıklı DMŞA’nın optimize edilen boyutları

(Optimized dimensions of symmetrical rod slot RMA)

\begin{tabular}{|c|c|c|c|}
\hline Parametreler & $\begin{array}{c}\text { Boyutlar } \\
(\mathrm{mm})\end{array}$ & Parametreler & $\begin{array}{c}\text { Boyutlar } \\
(\mathrm{mm})\end{array}$ \\
\hline$W_{p}$ & 4.4 & $L_{s}=L_{g}$ & 7.10 \\
\hline$L_{p}$ & 3.17 & $w_{50}$ & 1.56 \\
\hline$h$ & 0.508 & $g_{1}$ & 0.1 \\
\hline$t$ & 0.035 & $g_{2}$ & 0.1 \\
\hline$W_{s}=W_{g}$ & 8 & $g_{3}$ & 0.2 \\
\hline$w_{1}=w_{2}$ & 0.3 & $L_{50}$ & 2.875 \\
\hline$d_{1}=d_{2}$ & 0.3 & $F_{i}$ & 1.14 \\
\hline$L_{1}=L_{2}$ & 1.04 & & \\
\hline
\end{tabular}

Tablo 1'de simetrik çubuk yarıklara sahip DMŞA'nın optimize edilen boyutları verilmektedir. Mikroşerit anten, teorik formüllerle hesaplanan değerler ile HFSS benzetim programıyla modellenmiştir. Modellenen mikroşerit antenin teorik formüllerden elde edilen simülasyon sonuçlarını iyileştirmek için anten boyutlarında ufak değişiklikler yapılmıştır. Yamanın uzunluğu ve genişliği istenilen çalışma frekansını bulmak için değiştirilmiştir. Ayrıca besleme hattının genişliği empedans uyumluluğu için iyileştirilerek optimize edilmiştir.

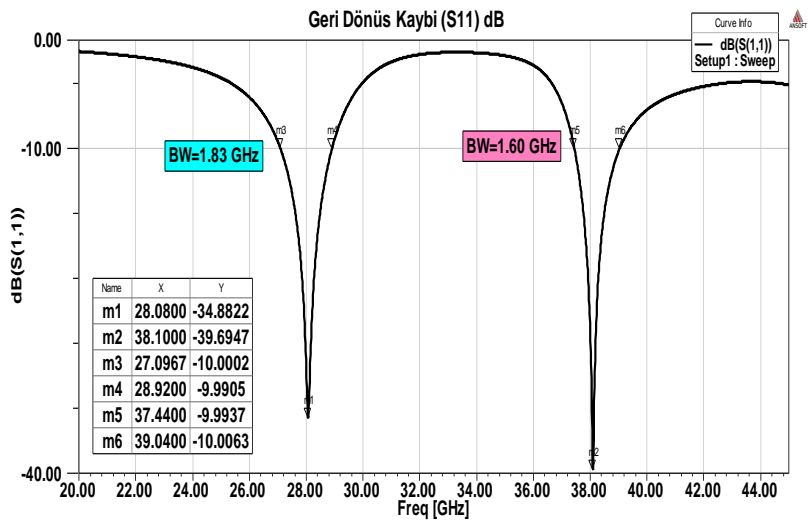

Şekil 4. Çift bantlı 28/38 GHz içeriden temassız beslenen DMŞA'nın geri dönüş kaybı

(Return loss of dual band $28 / 38 \mathrm{GHz}$ that is feed non-contacting RMA)

Şekil 4'te çift frekansta rezonansa giren içeriden temassız beslenen DMŞA için Geri Dönüş Kaybı $\left(S_{11}\right)$ grafiği gösterilmiştir. İlk frekans olan $28.08 \mathrm{GHz}$ için geri dönüş kaybı -34.88 dB ve bant genişliği ise $1.83 \mathrm{GHz}$ 'dir. $38 \mathrm{GHz}$ çalışma frekansında geri dönüş kaybı -39.69 dB bant genişliği $1.60 \mathrm{GHz}$ olarak bulunmaktadır. DMŞA'nın 28 GHz frekansı için kazanç paterni Şekil 5'de gösterilmiştir. DMŞA'nın $P h i=0$ ve $P h i=90$ yönlerindeki kazançları sırasıyla $8.14 \mathrm{~dB}$ ve $8.19 \mathrm{~dB}$ olarak bulunmuştur. Şekil 6'da ise $38 \mathrm{GHz}$ frekansı için kazanç paterni gösterilmiş olan DMŞA'nın $\mathrm{Phi}=0$ ve $\mathrm{Phi}=90$ yönlerindeki kazançları sırasıyla $6.64 \mathrm{~dB}$ ve $2.48 \mathrm{~dB}$ olarak bulunmuştur.

\subsection{Yarık Boyutları Değiştirilen Çift Bantlı 28/38 GHz} Içeriden Temassiz Beslenen DMŞA (Dual Band 28/38 GHz with Changed Slot Sizes non-contacting feed RMA)

Yama üzerine açılan yarıkların boyutlarının değişimi veya ekstra yarik eklenmesi ikinci frekansin empedans uyumluluğunu ve bant genişliğini etkilemektedir. Bir önceki tasarımdaki simetrik yarıklar değiştirilerek, her yarık iki çubuk yarıktan oluşmak üzere güncellenmiştir. Her çift yarık kalın ve ince yarıktan oluşacak şekilde tasarlanan yeni antenin geometrisi Şekil 8'de gösterilmektedir. Tablo 2'de yarık şekli ve boyutları değiştirilen DMŞA'nın parametreleri verilmiştir.

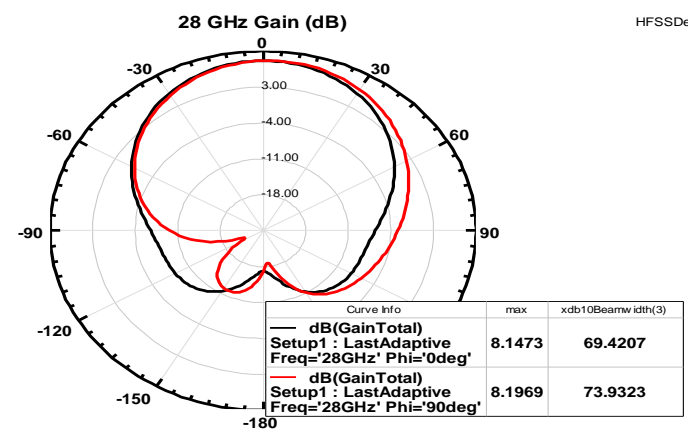

Şekil 5. Çift bantlı içeriden temassız beslenen DMŞA'nın kazanç paterni $(28 \mathrm{GHz})$

(Gain pattern of dual band $28 \mathrm{GHz}$ that is feed non-contacting RMA)

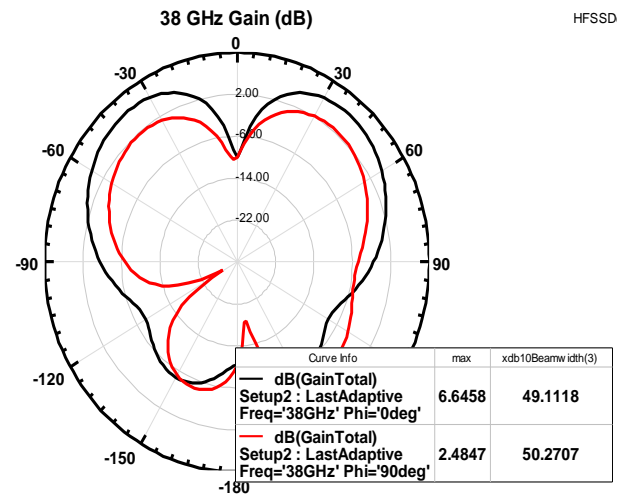

Şekil 6. Çift bantlı içeriden temassız beslenen DMŞA'nın kazanç paterni (38 GHz)

(Gain pattern of dual band $38 \mathrm{GHz}$ that is feed non-contacting RMA)

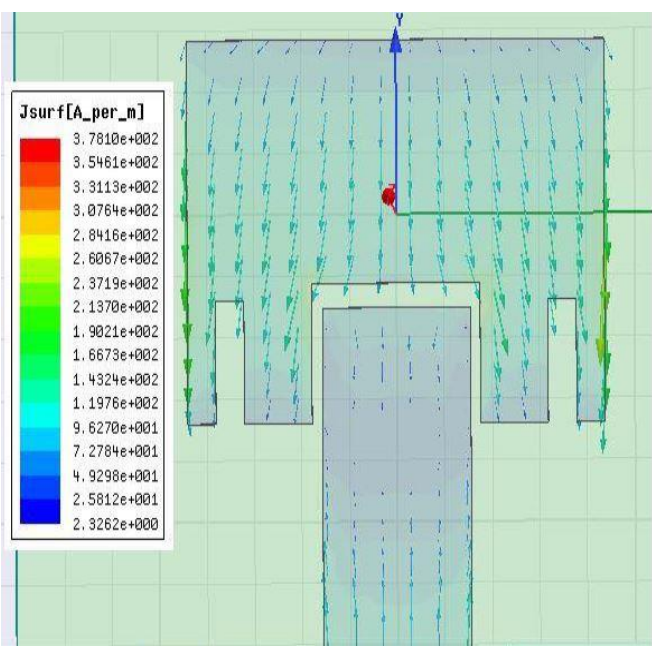

Şekil 7. Çift bantlı içeriden temassız beslenen DMŞA'nın yüzey akımları (Dual band feed without contact inside RMA surface currents)

Yarık boyutlarının değiştirilmesiyle ikinci frekansın bant genişliğinin $1.60 \mathrm{GHz}$ 'den $1.79 \mathrm{GHz}$ 'e yükseldiği Şekil 8 'de verilen geri dönüş kaybı grafiğinden görülmektedir. 
İlk frekans olan $28 \mathrm{GHz}$ 'in bant genişliği ise $1.83 \mathrm{GHz}$ olarak aynı kalmaktadır. Şekil 10'da yarık boyutları değiştirilen çift bantlı içeriden temassız beslenen DMŞA' nın $28 \mathrm{GHz}$ frekansı için kazanç paterni gösterilmiştir. Bu frekans için DMŞA'nın $\mathrm{Phi}=0$ ve $\mathrm{Phi}=90$ yönlerindeki kazançları sırasıyla $8.13 \mathrm{~dB}$ ve $8.17 \mathrm{~dB}$ olarak bulunmuştur. Şekil 11'de yarık boyutları değiştirilen çift bantlı içeriden temassız beslenen DMŞA'nın $38.12 \mathrm{GHz}$ frekansı için kazanç paterni gösterilmiştir. DMŞA'nın 38 $\mathrm{GHz}$ 'de $\mathrm{Phi}=0$ ve $\mathrm{Phi}=90$ yönlerindeki kazançları sırasıyla $6.71 \mathrm{~dB}$ ve $2.66 \mathrm{~dB}$ olarak bulunmuştur.

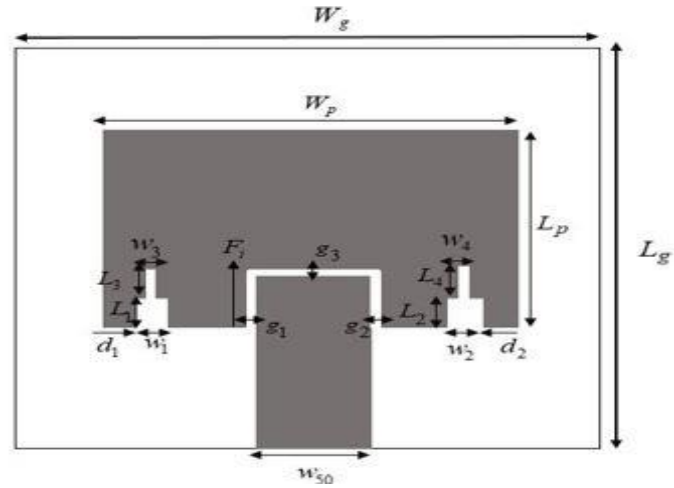

Şekil 8. Yarık boyutları değiştirilen içeriden temassız beslenen DMŞA

(Changed Slot Sizes non-contacting feed RMA)

Tablo 2. Yarık boyutları değiştirilen içeriden temassız beslenen DMŞA'nın optimize edilen boyutları (Optimized dimensions of the RMA which is feed non-contacting slot dimension change)

\begin{tabular}{|c|c|c|c|}
\hline Parametreler & $\begin{array}{c}\text { Boyutlar } \\
(\mathrm{mm})\end{array}$ & Parametreler & $\begin{array}{c}\text { Boyutlar } \\
(\mathrm{mm})\end{array}$ \\
\hline$W_{p}$ & 4.4 & $L_{s}=L_{g}$ & 7.10 \\
\hline$L_{p}$ & 3.18 & $w_{50}$ & 1.56 \\
\hline$h$ & 0.508 & $g_{1}$ & 0.1 \\
\hline$t$ & 0.035 & $g_{2}$ & 0.1 \\
\hline$W_{s}=W_{g}$ & 8 & $g_{3}$ & 0.2 \\
\hline$w_{1}=w_{2}$ & 0.6 & $L_{50}$ & 2.875 \\
\hline$d_{1}=d_{2}$ & 0.2 & $F_{i}$ & 1.14 \\
\hline$L_{1}=L_{2}$ & 0.4 & $L_{3}$ & 1.15 \\
\hline$w_{3}=w_{4}$ & 0.2 & $L_{4}$ & 1.15 \\
\hline
\end{tabular}

3.3. Çift Bantlı (28/38 GHz) Iç̧eriden Temassız Beslenen Çok Katmanlı (Yığın) DMŞA (Dual Band 28/38 GHz Insert Feed Non-Contacting Multi-Layer (Stacked) RMA)

$\mathrm{Bu}$ çalışmada bant genişliğini arttıran yöntemlerden biri olan yığın yama yöntemi çift bantlı $(28 / 38 \mathrm{GHz})$ içeriden temassız beslenen DMŞA'ya uygulanmıştır. Simetrik çentik yarıklara sahip ana yama üzerine dieletrik sabiti $\varepsilon_{r}=2.2$ ve malzeme kalınlığ $0.508 \mathrm{~mm}$ olan ikinci bir RT Duroid 5880 alttaşı kullanıldı. Bu ikinci fakat diğeri ile aynı dielektrik malzeme üstüne ise ana yamadan daha küçük boyutta olan parazit yama eklenmiştir. Besleme hattı yarıklı ana yamanın uzantısı şeklinde temassız besleme yöntemi kullanılarak iki dielektrik malzeme arasından besleme yapılmıştır. Simülasyon programında oluşturulan bu DMŞA geometrisinin 3 boyutlu görünümü Şekil 13'de verilmiştir.
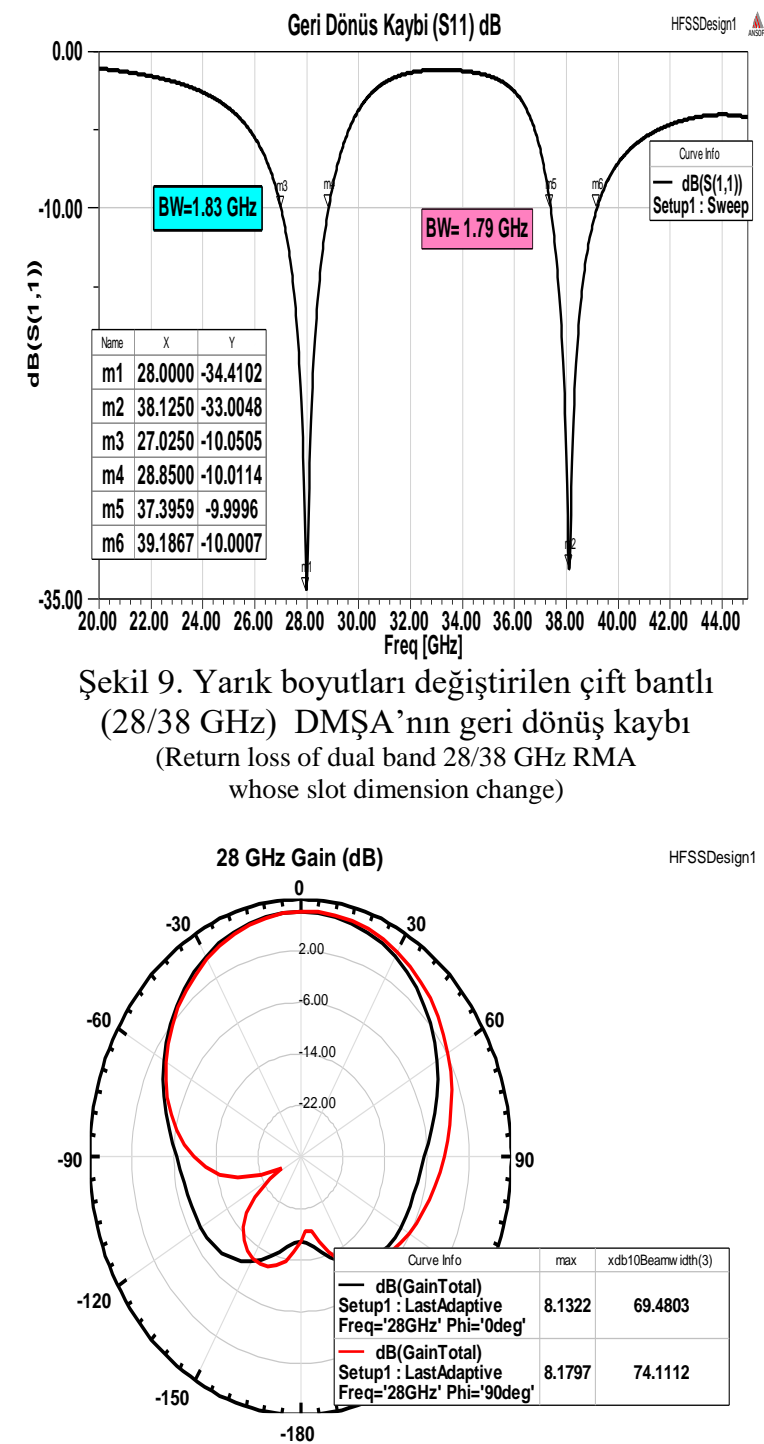

Şekil 10. Yarık boyutları değiştirilen çift bantlı DMŞA'nın kazanç paterni (28 GHz) (Gain Pattern of dual band GHz RMA whose slot dimension change $(28 \mathrm{GHz}))$

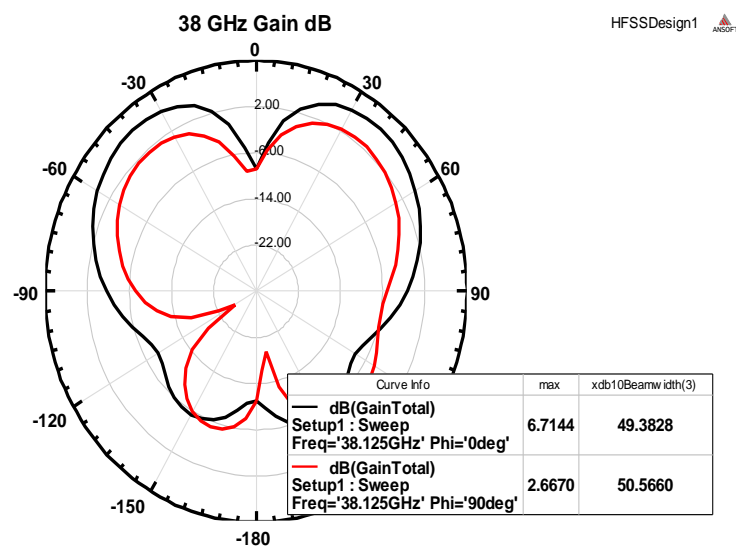

Şekil 11. Yarık boyutları değiştirilen çift bantlı DMŞA'nın kazanç paterni (38 GHz)

(Gain Pattern of dual band GHz RMA

whose slot dimension change $(38 \mathrm{GHz}))$ 


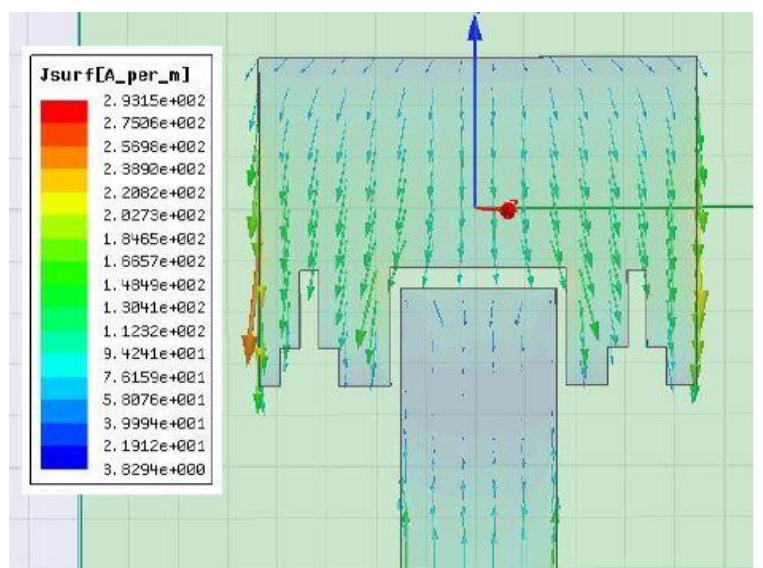

Şekil 12. Yarık boyutları değiştirilen çift bantlı içeriden temassız beslenen DMŞA'nın yüzey akımları

(Surface currents of the dual band RMA, whose slot dimensions are changed, which is fed without contact from the inside)

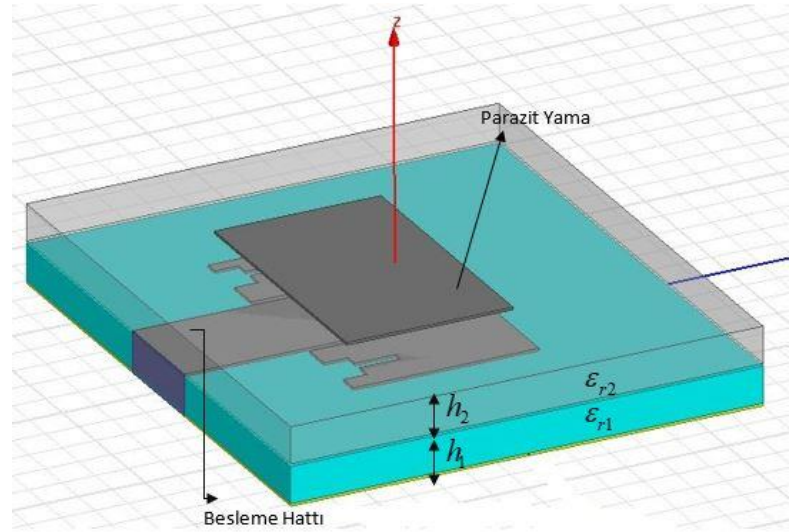

Şekil 13. Çift bantlı (28/38 GHz) içeriden temassız beslenen yığın DMŞA'nın 3B Görünümü (İnsert feed non-contacting stacked RMA 28/38 GHz 3D view)

Şekil 14'te çift frekansta rezonansa giren içeriden temassız beslenen yığın dikdörtgen mikroşerit antene ait geri dönüş kaybı grafiği gösterilmiştir. İlk frekans olan $27.95 \mathrm{GHz}$ için geri dönüş kaybı -29.45 dB ve bant genişliği ise $3.65 \mathrm{GHz}$ dir. 38.07 GHz frekansı için geri dönüş kaybı -21.18 dB bant genişliği ise $3.55 \mathrm{GHz}$ olarak bulunmuştur.

Şekil 15'te görüldüğü gibi DMŞA'nın 28 GHz'de Phi=0 ve Phi=90 yönlerindeki kazançları sırasıyla $7.86 \mathrm{~dB}$ ve 7.90 dB olarak bulunmuştur. Şekil 16'da tasarımı yapılan DMŞA' nın $38 \mathrm{GHz}$ frekansı için kazanç paterni gösterilmiştir. DMŞA'nın $\mathrm{Phi}=0$ ve $\mathrm{Phi}=90$ yönlerindeki kazançları sırasıyla $6.27 \mathrm{~dB}$ ve $4.18 \mathrm{~dB}$ olarak bulunmuştur.

\section{4. Çift Bantlı 28/38 GHz Yakınlık Kuplajlı DMŞA (Dual Band 28/38 GHz Proximity Coupled RMA)}

Yakınlık kuplaj besleme yöntemiyle DMŞA'nın 28/38 $\mathrm{GHz}$ frekanslarında çift bantta rezonansa girmesi için yamanın kenarlarından simetrik olarak çubuk şeklinde yarıklar açılmıştır. $\mathrm{Bu}$ besleme yönteminde besleme hattı iki dielektrik malzeme arasında ve 1şıma yapan mikroşerit yama en üsttedir. Daha önceki tasarımlarda kullanılan çubuk şeklinde yarıkların yama üzerindeki konumları ikinci frekans için optimize edilmiştir. Anten geometrisi Şekil 19'da ve 3 boyutlu simülasyon görüntüsü Şekil 20'de verilmiştir.
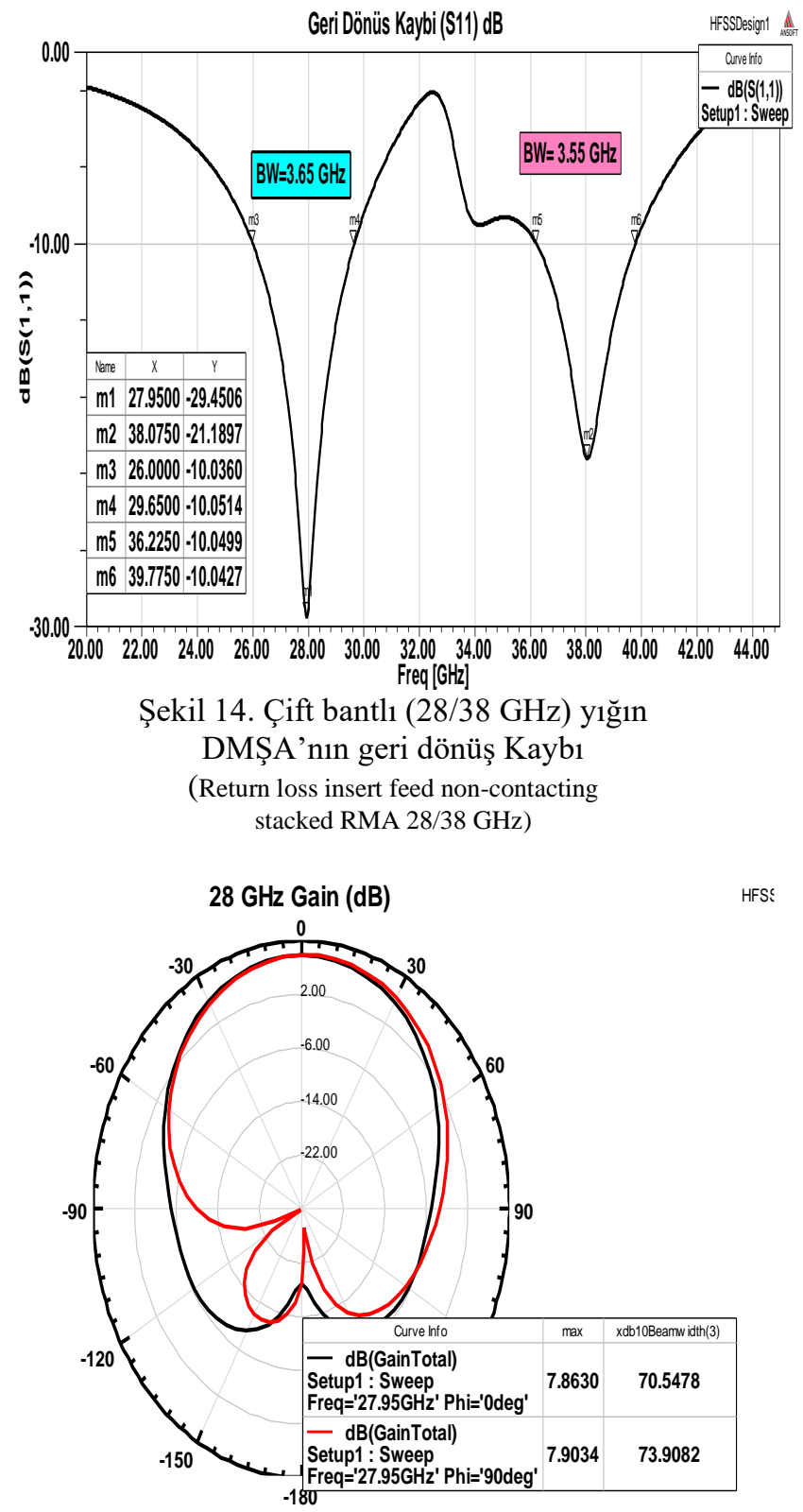

Şekil 15. Çift bantlı yı̆̆ın DMŞA'nın
kazanç paterni (28 GHz)
(Dual band stacked RMA $28 \mathrm{GHz}$ gain pattern)

Şekil 21'de BTY'siz yakınlık kuplajlı çift bantlı DMŞA'nın geri dönüş kaybı grafiği gösterilmiştir. İki frekans için de geri dönüş kayıplarının yüksek olması anten veriminin iyi olmadığını göstermektedir. Yakınlık kuplajlı besleme yönteminde yama ve toprak düzlemi arasında iki dielektrik malzemenin kullanılması sahte radyasyonları tetiklediğinden empedansta uyumsuzluk meydana gelmektedir. Empedans uyumluluğunu sağlamak için toprak yüzeyine halka şeklinde yarık açılarak toprak 
yüzeyi bozulmuştur. Halka yarıklı DMŞA'nın görünümü Şekil 22' de gösterilmektedir.

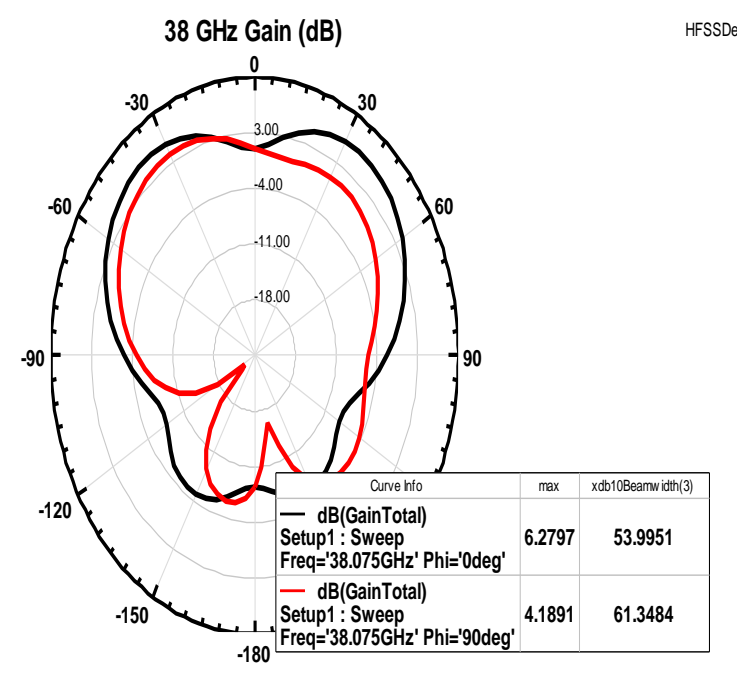

Şekil 16. Çift bantlı yığın DMŞA'nın kazanç paterni $(38 \mathrm{GHz})$

(Dual band stacked RMA $38 \mathrm{GHz}$ gain pattern)

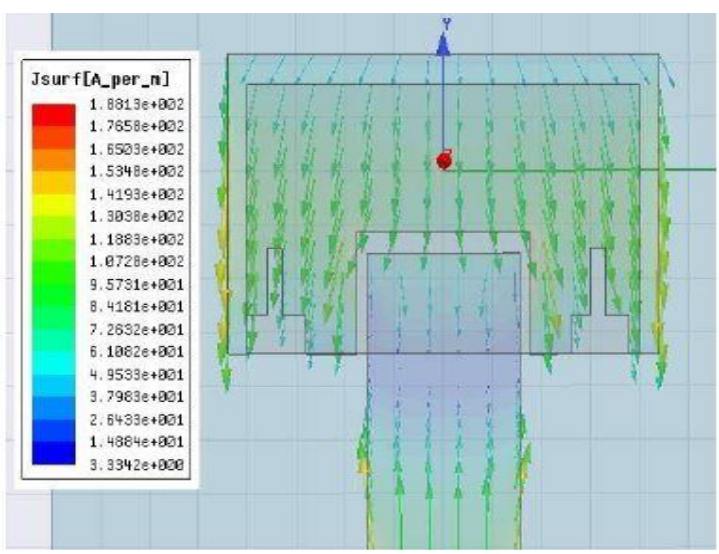

Şekil 17. Çift bantlı yığın DMŞA ana yama akım dağılımı (Dual band stack RMA main patch current distribution)

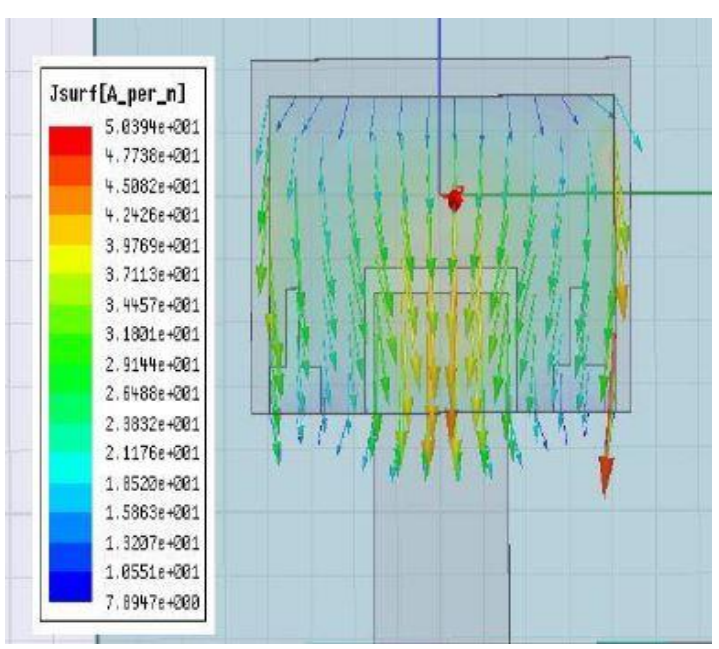

Şekil 18. Çift bantlı yı̆̆ın DMŞA parazit yama akım dağılımı

(Dual band stack RMA parasite patch current distribution)

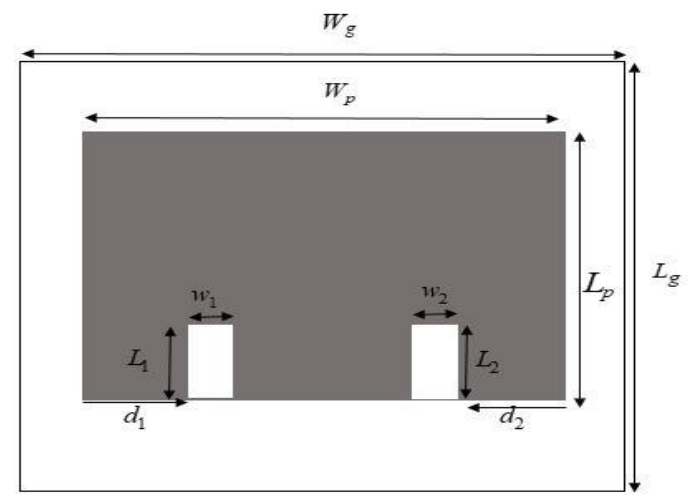

Şekil 19. Çift bantlı 28/38 GHz yakınlık kuplajlı DMŞA'nın yama düzlemi

(Patch plane of dual band 28/38 GHz proximity RMA)

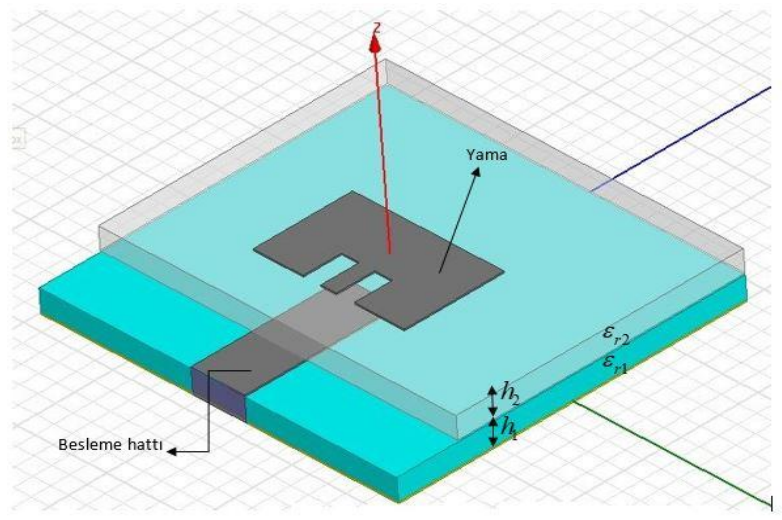

Şekil 20. Çift bantlı 28/38 GHz yakınlık kuplajlı DMŞA'nın 3B görünümü

(3D view of dual band 28/38 GHz proximity coupled RMA)

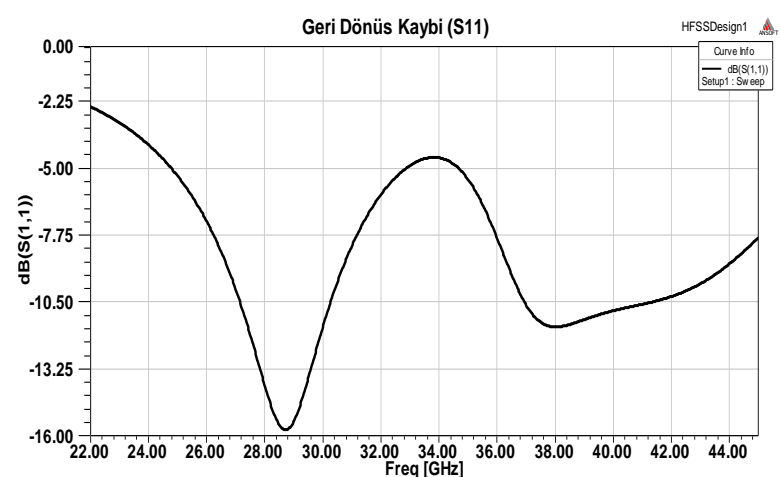

Şekil 21. BTY'siz yakınlık kuplajlı çift bantlı DMŞA'nın geri dönüş kaybı

(Return loss of proximity coupled dual band RMA without DGS)

Şekil 22'de bozulmuş toprak yüzeyine sahip bu yeni DMŞA tasarımının toprak yüzeyinden bakıldığında elde edilen görüntüsü verilmiştir. Şekilden de görüldüğü gibi, toprak yüzeyine halka şeklinde yarık açılmıştır. Bu durumda antenin rezonans frekansında oluşan kaymayı engellemek için yama uzunluğu azaltılıp, yarık boyutları tekrar optimize edilmiştir. Tablo 3'te yakınlık kuplajlı beslenen ve bozulmuş toprak yüzeyi (BTY) uygulanan çift bantlı (28/38 GHz) DMŞA'nın optimize edilen boyutları verilmiştir. 


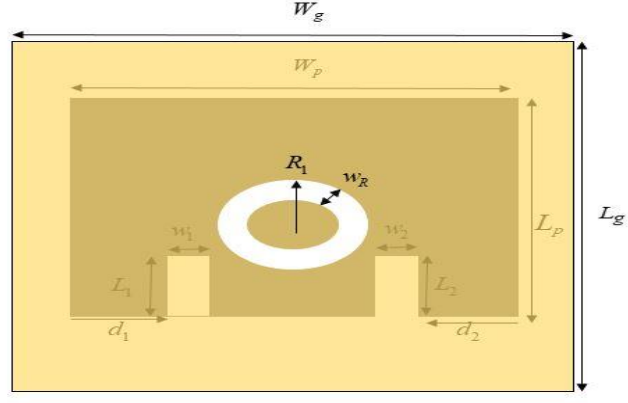

Şekil 22. BTY'li çift bantlı

(28/38 GHz) yakınlık kuplajlı DMȘA

(Dual band with DGS $28 / 38 \mathrm{GHz}$ proximity coupled RMA)

Tablo 3. Çift bantlı (28/38 GHz) yakınlık kuplajlı

DMŞA'nın optimize edilen boyutları

(Optimized dimensions of dual-band 28/38 GHz proximity coupled RMA)

\begin{tabular}{|c|c|c|c|}
\hline Parametreler & $\begin{array}{c}\text { Boyutlar } \\
(\mathrm{mm})\end{array}$ & Parametreler & $\begin{array}{c}\text { Boyutlar } \\
(\mathrm{mm})\end{array}$ \\
\hline$W_{p}$ & 4.23 & $L_{s}=L_{g}$ & 6 \\
\hline$L_{p}$ & 2.6 & $W_{s}=W_{g}$ & 7 \\
\hline$h_{1}$ & 0.508 & $w_{1}$ & 0.5 \\
\hline$h_{2}$ & 0.508 & $w_{2}$ & 0.5 \\
\hline$d_{1}$ & 1.4 & $L_{1}$ & 1 \\
\hline$d_{2}$ & 1.4 & $L_{2}$ & 1 \\
\hline$w_{R}$ & 0.3 & $R_{1}$ & 0.6 \\
\hline
\end{tabular}

Şekil 23'te verilen grafikte, bozulmuş toprak yüzeyi yöntemi sonucu, $28.07 \mathrm{GHz}$ için geri dönüş kaybının $32.27 \mathrm{~dB}$ ve bant genişliğinin $4.79 \mathrm{GHz}, 38.02 \mathrm{GHz}$ frekansı için ise geri dönüş kaybının $-40.42 \mathrm{~dB}$ ve bant genişliğinin $5.67 \mathrm{GHz}$ olarak bulunduğu görülmektedir.

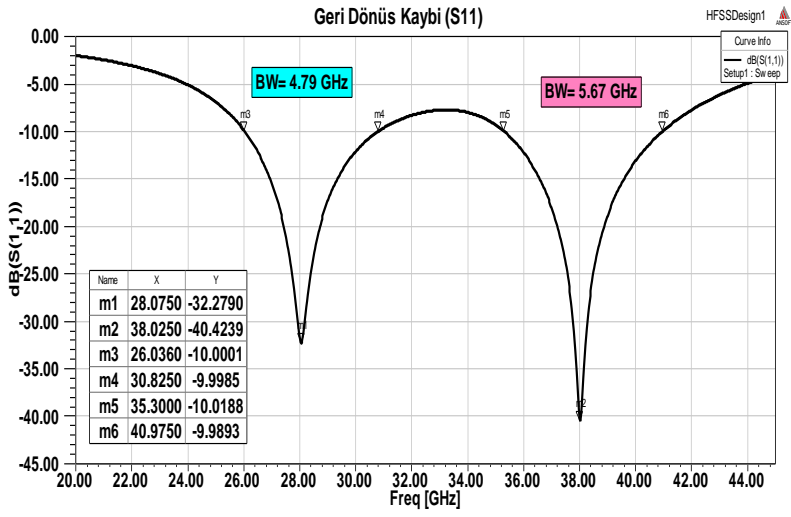

Şekil 23. BTY'li çift bantlı (28/38 GHz) yakınlık kuplajlı

DMŞA'nın geri dönüş kaybı

(Return loss of proximity coupled RMA dual band 28/38 GHz with DGS )

Şekil 24'te bozulmuş toprak yüzeyi yöntemi uygulanan, çift bantlı 28/38 GHz, yakınlık kuplajlı DMŞA'nın 28.07 GHz frekansı için kazanç paterni gösterilmiştir. DMŞA'nın Phi $=0$ ve $P h i=90$ yönlerindeki kazançları sırasıyla $7.80 \mathrm{~dB}$ ve $8.16 \mathrm{~dB}$ olarak bulunmuştur. Şekil 25 'te çift bantlı 28/38 GHz yakınlık kuplajı DMŞA'nın $38.02 \mathrm{GHz}$ frekansı için kazanç paterni gösterilmiş, DMŞA'nın Phi=0 ve Phi=90 yönlerindeki kazançları sırasıyla $6.59 \mathrm{~dB}$ ve $1.49 \mathrm{~dB}$ olarak bulunmuştur.

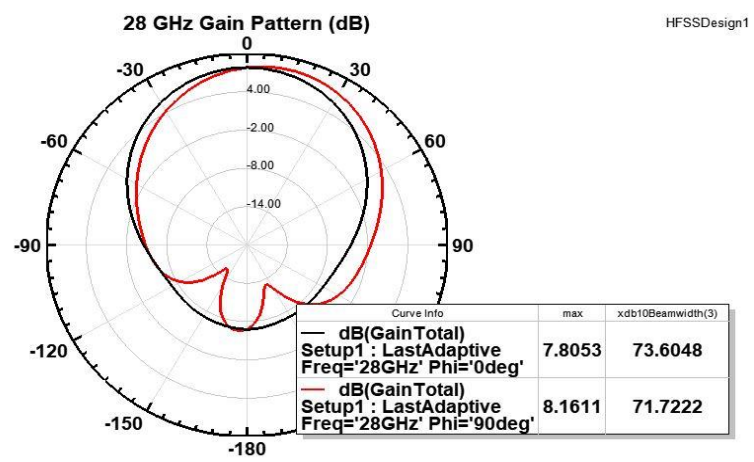

Şekil 24. BTY'li çift bantlı DMŞA'nın kazanç paterni $(28 \mathrm{GHz})$

(Gain pattern of dual band RMA with DGS $(28 \mathrm{GHz})$ )

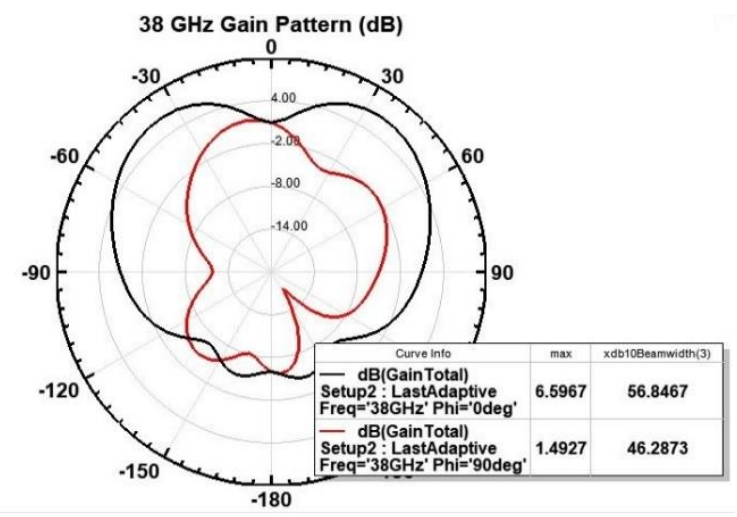

Şekil 25. BTY'li çift bantlı DMŞA'nın kazanç paterni $(38 \mathrm{GHz})$

(Gain pattern of dual band RMA with DGS $(38 \mathrm{GHz})$ )

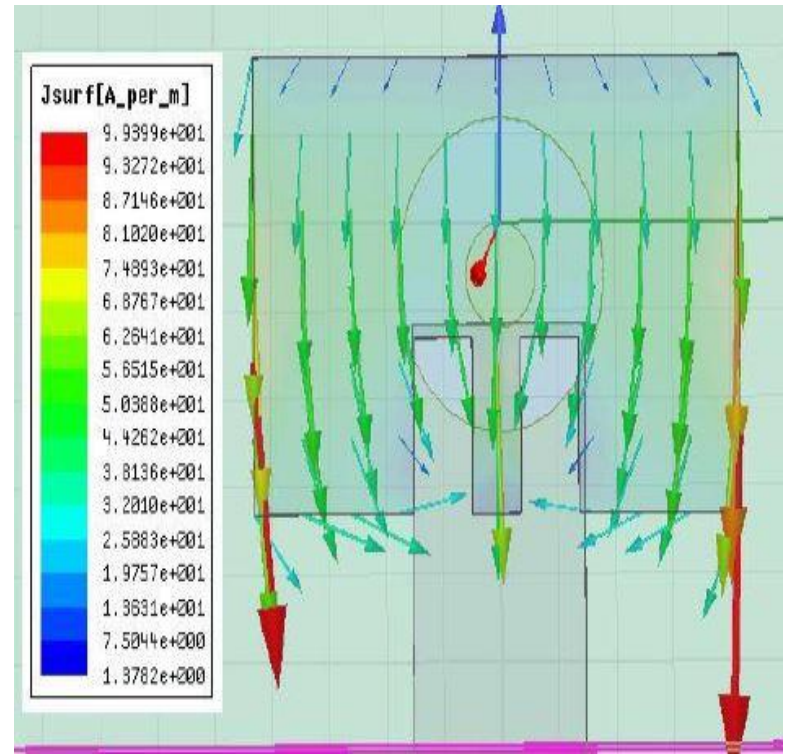

Şekil 26. BTY'li çift bantlı (28/38 GHz) yakınlık kuplajlı DMŞA'nın akım dağılımı (Current distribution of dual-band $(28 / 38 \mathrm{GHz})$ proximity coupling RMA with DGS)

\section{BULGULAR VE TARTIŞMA (FINDINGS AND DISCUSSION)}

$\mathrm{Bu}$ çalışmada $5 \mathrm{G}$ teknolojisi için dört farklı çift bantta (28/38GHz) yayılım yapan DMŞA tasarımı yapılmıştır. Bütün tasarımlarda anten boyutları $28 \mathrm{GHz}$ frekansı temel 
alınarak ve iletim hattı modeli kullanılarak yaklaşık olarak tahmin edilmiştir. Daha sonrasında anten yüzeyine simetrik yarıklar açılarak antenin $38 \mathrm{GHz}$ 'de de rezonansa girmesi için yarık ve anten boyutları simülasyonlar yardımıyla optimize edilmiştir.

İlk iki tasarımda içerden temassız mikroşerit besleme yöntemi kullanılmış ve anten üzerine açılan yarık boyutları değiştirilerek anten parametrelerine etkisi gözlenmiştir. Bir sonraki tasarımda içerden temassız mikroşerit besleme ile uyarılan DMŞA'ya yığın yama eklenerek bant genişliğine etkisi gözlemlenmiştir. En son tasarımda ise yakınlık kuplajlı besleme tekniği uygulanmış ve bant genişliğini arttırmak için bozulmuş toprak yüzeyi yöntemi denenmiştir. Tablo 4'de bütün tasarımların simülasyon sonuçları özetlenmiştir. Tasarımlarda en iyi sonuçlar yakınlık kuplajlı beslenen ve bozulmuş toprak yüzeyine sahip DMŞA tasarımı ile elde edilmiştir. Bu tasarımda 28.07 GHz için bant genişliği 4.79 GHz, kazancı $8.16 \mathrm{~dB}$ ve $38.02 \mathrm{GHz}$ için bant genişliği $5.67 \mathrm{GHz}$, kazancı ise $7.06 \mathrm{~dB}$ olarak bulunmuştur. Ayrıca geri dönüş kaybı da her iki frekans için oldukça düşüktür.

Tablo 5 incelendiğinde, Ref. [7] ve [8]'deki çift bantlı mikroşerit antenler çok katmanlı ve yakınlık kuplaj beslemeli olması nedeniyle bant genişlikleri bu tezdeki yapılan DMŞA tasarımına göre yüksek değerlerdedir. Fakat bu referans tasarımlarının kazançlarındaki düşme dikkat çekmekte ve bunun da anten verimini etkileyen bir başka sorun olduğu bilinmektedir. Ref. [11]'deki mikroşerit anten çalışmasında kazanç ve bant genişliği değerleri daha yüksek olup geri dönüş kaybı değerleri bu çalışmadaki 28/38 GHz yakınlık kuplaj DMŞA'nın geri dönüş kaybı değerlerine oranla daha yüksektir. Geri dönüş kaybının yüksek olması da anten verimliliğini olumsuz etkileyen bir diğer faktördür.

Ref. [14]'de iki katmanlı ve bozulmuş toprak yüzeyi kullanılarak oluşturulmuş dairesel yamaya sahip mikroşerit anten tasarımı yapılmıştır. Ref. [14]'de geri dönüş kaybını ve bant genişliğini iyileştirmek için toprak yüzeyine $F$ şekilli yarıklar açılmıştır. Bu çalışmadaki en iyi sonuçları el de ettiğimiz, yakınlık kuplajlı, 28/38 GHz DMŞA tasarımı Ref. [14]'deki mikroşerit antenin bant genişliği ve kazancına kıyasla daha iyi bir değere sahiptir. Ayrıca her iki frekans değeri için de elde ettiğimiz -30dB altındaki geri dönüş kayıpları da anten verimliliğinin de oldukça yüksek olduğunu göstermektedir.

Şekil 27'de mikroşerit anten tasarımların geri dönüş kaybı ve bant genişlikleri karşılaştırmalı olarak grafikle gösterilmiştir. $\mathrm{Bu}$ grafik incelendiğinde en yüksek bant genişliği halka yarıklı bozulmuş toprak yüzeyine sahip yakınlık kuplaj ile beslenen mikroşerit antene ait olduğu görülmektedir.

\section{SONUÇ (CONCLUSION)}

$\mathrm{Bu}$ çalışmada simülasyonu yapılan çift bant $(28 / 38 \mathrm{GHz})$ DMŞA tasarımları arasında en yüksek bant genişliği yakınlık kuplajlı beslenen ve bozulmuş toprak yüzeyi uygulanan DMŞA tasarımıdır. Bu tasarımda iki katmanlı yap1 ve bozulmuş toprak yüzeyi bant genişliği ve geri dönüş kaybını iyileştirmiştir. $28 \mathrm{GHz}$ frekansı için geri dönüş kaybı, bant genişliği ve kazanç değerleri sırasıyla $32.27 \mathrm{~dB}, 4.79 \mathrm{GHz}$ ve $8.16 \mathrm{~dB}$ olarak bulunmuştur. İkinci frekans olan $38 \mathrm{GHz}$ için ise geri dönüş kaybı, bant genişliği ve kazanç değerleri sırasıyla $-40.42 \mathrm{~dB}, 5.67 \mathrm{GHz}$ ve $7.06 \mathrm{~dB}$ olarak HFSS benzetim programıla hesaplanmıştır. Bu sonuçlara bütünüyle bakıldığında, literatürde karşılaştırma yapılan diğer anten türlerine göre daha verimli bir anten tasarımı yapıldığını göstermektedir. Literatürdeki diğer anten türlerine göre yığın ve yakınlık kuplajlı mikroşerit antenlerin boyutları daha küçük, yüksek kazançlı, düşük geri dönüş kaybına sahip ve geniş bantta yayın yapmaktadır.

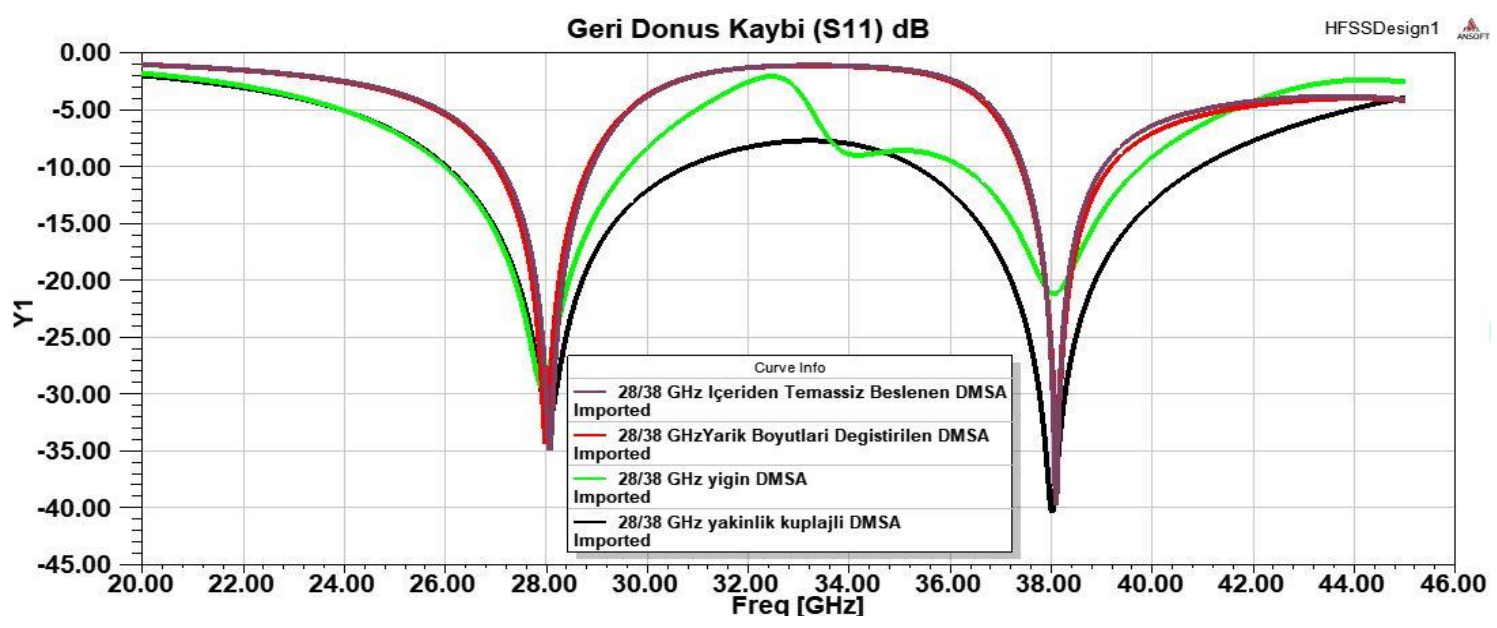

Şekil 27. Çift bantlı 28/38 GHz DMŞA tasarımlarının geri dönüş kaybı ve bant genişlikleri (Return loss and bandwidths of dual-band $28 / 38 \mathrm{GHz}$ RMA designs) 
Tablo 4. Çift bantlı 28/38 GHz DMŞA simülasyon sonuçlarının karşılaştırılması (Comparison of dual band 28/38 GHz RMA simulation results)

\begin{tabular}{|c|c|c|c|c|}
\hline Simülasyon Sonuçları & \multicolumn{2}{|c|}{$\begin{array}{c}\text { Çift Bantlı } 28 / 38 \mathrm{GHz} \text { İçeriden } \\
\text { Temassız Beslenen DMŞA }\end{array}$} & \multicolumn{2}{|c|}{$\begin{array}{c}\text { Yarık Boyutları Değiştirilen Çift Bantlı } \\
28 / 38 \mathrm{GHz} \text { DMŞA }\end{array}$} \\
\hline Rezonans Frekansı & $28.08 \mathrm{GHz}$ & $38.10 \mathrm{GHz}$ & $28.00 \mathrm{GHz}$ & $38.12 \mathrm{GHz}$ \\
\hline Geri Dönüş Kaybı & $-34.88 \mathrm{~dB}$ & $-39.69 d B$ & $-34.41 \mathrm{~dB}$ & $-33.00 \mathrm{~dB}$ \\
\hline Duran Dalga Oranı & 1.036 & 1.02 & 1.036 & 1.02 \\
\hline Bant Genişliği & $1.83 \mathrm{GHz}$ & $1.60 \mathrm{GHz}$ & $1.83 \mathrm{GHz}$ & $1.79 \mathrm{GHz}$ \\
\hline Kazanç & $8.19 \mathrm{~dB}$ & $6.78 \mathrm{~dB}$ & $8.19 \mathrm{~dB}$ & $6.71 \mathrm{~dB}$ \\
\hline Simülasyon Sonuçları & \multicolumn{2}{|c|}{$\begin{array}{l}\text { Çift bantlı }(28 / 38 \mathrm{GHz}) \text { içeriden } \\
\text { temassız beslenen yığın DMŞA }\end{array}$} & \multicolumn{2}{|c|}{$\begin{array}{l}\text { Çift bantlı (28/38 GHz) } \\
\text { yakınlık kuplajlı DMŞA }\end{array}$} \\
\hline Rezonans Frekansı & $27.95 \mathrm{GHz}$ & $38.07 \mathrm{GHz}$ & $28.07 \mathrm{GHz}$ & $38.02 \mathrm{GHz}$ \\
\hline Geri Dönüş Kaybı & $-29.45 \mathrm{~dB}$ & $-21.18 d B$ & $-32.27 \mathrm{~dB}$ & $-40.42 \mathrm{~dB}$ \\
\hline Duran Dalga Oranı & 1.036 & 1.02 & 1.036 & 1.02 \\
\hline Bant Genişliği & $3.65 \mathrm{GHz}$ & $3.55 \mathrm{GHz}$ & $4.79 \mathrm{GHz}$ & $5.67 \mathrm{GHz}$ \\
\hline Kazanç & $7.90 \mathrm{~dB}$ & $6.93 \mathrm{~dB}$ & $8.16 \mathrm{~dB}$ & $7.06 \mathrm{~dB}$ \\
\hline
\end{tabular}

Tablo 5. 28/38 GHz DMŞA simülasyon sonuçlarının literatürdeki sonuçlarla karşılaştırılması (Comparison of $28 / 38 \mathrm{GHz}$ RMA simulation results with the results in the literature)

\begin{tabular}{|c|c|c|c|c|c|c|c|c|c|}
\hline \multirow[t]{2}{*}{$\begin{array}{l}\text { Mikroşerit } \\
\text { Antenler }\end{array}$} & \multicolumn{2}{|c|}{ Rezonans Frekansı } & \multicolumn{2}{|c|}{$\begin{array}{l}\text { Geri Dönüş Kaybı } \\
\left(S_{11}\right)\end{array}$} & \multicolumn{2}{|c|}{ Bant Genişliği } & \multicolumn{2}{|c|}{ Kazanç } & \multirow[t]{2}{*}{$\begin{array}{l}\text { Anten Boyutları } \\
\left(\mathrm{W} \times \mathrm{L} \times \mathrm{h} \mathrm{mm}^{3}\right)\end{array}$} \\
\hline & $f_{r 1}$ & $f_{r 2}$ & $f_{r 1}$ & $f_{r 2}$ & $f_{r 1}$ & $f_{r 2}$ & $f_{r 1}$ & $f_{r 2}$ & \\
\hline [7] & $28 \mathrm{GHz}$ & $38 \mathrm{GHz}$ & $-21.5 \mathrm{~dB}$ & $-21 d B$ & $\begin{array}{c}10 \\
\mathrm{GHz}\end{array}$ & $7 \mathrm{GHz}$ & $\begin{array}{l}4.2 \\
d B\end{array}$ & $6.9 \mathrm{~dB}$ & $\begin{array}{c}8 \times 7.5 \times 0.127 \\
\left(\mathrm{~mm}^{3}\right)\end{array}$ \\
\hline [8] & $26.5 \mathrm{GHz}$ & $38 \mathrm{GHz}$ & $-46 d B$ & $-22 d B$ & $7 \mathrm{GHz}$ & $\begin{array}{l}6.5 \\
\mathrm{GHz}\end{array}$ & $\begin{array}{l}3.6 \\
d B\end{array}$ & $\begin{array}{c}4.45 \\
d B\end{array}$ & $\begin{array}{c}5 \times 5 \times 0.127 \\
\left(\mathrm{~mm}^{3}\right)\end{array}$ \\
\hline [11] & $28 \mathrm{GHz}$ & $38 \mathrm{GHz}$ & $-29 d B$ & $-26 d B$ & $\begin{array}{l}5.95 \\
\mathrm{GHz}\end{array}$ & $\begin{array}{l}4.95 \\
\mathrm{GHz}\end{array}$ & $\begin{array}{c}8.63 \\
d B\end{array}$ & $\begin{array}{c}8.62 \\
d B\end{array}$ & $\begin{array}{c}7.5 \times 4.6 \times 0.508 \\
\left(\mathrm{~mm}^{3}\right)\end{array}$ \\
\hline [14] & $28 \mathrm{GHz}$ & $38 \mathrm{GHz}$ & $\begin{array}{c}-48.17 \\
d B\end{array}$ & $\begin{array}{c}-40.25 \\
d B\end{array}$ & $\begin{array}{l}4.51 \\
\mathrm{GHz}\end{array}$ & $\begin{array}{l}4.27 \\
\mathrm{GHz}\end{array}$ & $\begin{array}{l}6.0 \\
d B\end{array}$ & $6.3 \mathrm{~dB}$ & $\begin{array}{c}5 \times 5 \times 0.75 \\
\left(\mathrm{~mm}^{3}\right)\end{array}$ \\
\hline $\begin{array}{l}\text { Yığın } \\
\text { DMŞA }\end{array}$ & $\begin{array}{c}27.95 \\
\mathrm{GHz}\end{array}$ & $\begin{array}{c}38.07 \\
\mathrm{GHz}\end{array}$ & $\begin{array}{c}-29.45 \\
d B\end{array}$ & $\begin{array}{c}-21.18 \\
\mathrm{~dB}\end{array}$ & $\begin{array}{l}3.65 \\
\mathrm{GHz}\end{array}$ & $\begin{array}{l}3.55 \\
\mathrm{GHz}\end{array}$ & $\begin{array}{c}7.90 \\
\mathrm{~dB}\end{array}$ & $\begin{array}{c}6.93 \\
d B\end{array}$ & $\begin{array}{c}4.4 \times 2.8 \times 0.508 \\
\left(\mathrm{~mm}^{3}\right)\end{array}$ \\
\hline $\begin{array}{l}\text { Yakınlık } \\
\text { Kuplaj } \\
\text { DMŞA } \\
\text { (BTY) }\end{array}$ & $\begin{array}{c}28.07 \\
\mathrm{GHz}\end{array}$ & $\begin{array}{c}38.02 \\
\mathrm{GHz}\end{array}$ & $\begin{array}{c}-32.27 \\
d B\end{array}$ & $\begin{array}{c}-40.42 \\
d B\end{array}$ & $\begin{array}{l}4.79 \\
\mathrm{GHz}\end{array}$ & $\begin{array}{l}5.67 \\
\mathrm{GHz}\end{array}$ & $\begin{array}{c}8.16 \\
d B\end{array}$ & $\begin{array}{c}7.06 \\
d B\end{array}$ & $\begin{array}{c}4.23 \times 2.6 \times 0.508 \\
\left(\mathrm{~mm}^{3}\right)\end{array}$ \\
\hline
\end{tabular}

\section{KAYNAKLAR (REFERENCES)}

[1] Y. Yang, J. Xu, G. Shi, C.-X. Wang, 5G Wireless Systems 5G Wirel. Syst. Simul. Eval. Tech., New York, USA, Springer, 2017.

[2] B. Kalra, D. Chauhan, "A Comparative Study of Mobile Wireless Communication Network: $1 \mathrm{G}$ to 5G", Int. J. Comput. Sci. Inf. Technol. Res. 2, 430-433, 2014.

[3] Türk Telekom 5G+ Bilgi Notu Beyaz Kitap,Türkiye, 2018.

[4] Internet: $5 \mathrm{G}$ integration with $4 \mathrm{G}$, https://digitalwholesalesolutions.com/2019/12/beginners-guideto $5 \mathrm{~g} /, 05.06 .2020$.

[5] 5G and spectrum different approaches, Cullen İnternational, Cullen İnternational, Lome, Rebuplic of Togo, 2019.
[6] C. Seker, M.T. Güneser, T. Ozturk, "A Review of Millimeter Wave Communication for 5G", 2nd Int. Symp. Multidiscip. Stud. Innov. Technol.,1-5, 2018.

[7] O.M. Haraz, M.M.M. Ali, S. Alshebeili, A. Sebak, "Design of a 28/38 GHz dual-band printed slot antenna for the future $5 \mathrm{G}$ mobile communication Networks", 2015 IEEE Int. Symp. Antennas Propag. Usn. Natl. Radio Sci. Meet., 1532-1533, 2015.

[8] M. M. M. Ali, O. Haraz, S. Alshebeili, "Design of a dual-band printed slot antenna with utilizing a band rejection element for the 5G wireless applications" IEEE Int. Symp. Antennas Propag., 1865-1866., 2016.

[9] J. L. Li, M. H. Luo, H. Liu, "Design of a slot antenna for future 5G wireless communication systems", Prog. Electromagn. Res. Symp, 739-741, 2017. 
[10] H. Ullah, F.A. Tahir, M.U. Khan, "Dual-band planar spira monopole antenna for $28 / 38 \mathrm{GHz}$ frequency bands", IEEE Int. Symp. Antennas Propag. Usn. Natl. Radio Sci. Meet., 761-762, 2017.

[11] M.K.M. Amin, M.F. Mansor, N. Misran, M.T. Islam, "28/38GHz dual band slotted patch antenna with proximity-coupled feed for 5G communication", Int. Symp. Antennas Propag, 1-2, 2017.

[12] S. S. Haider, F. A. Tahir, H. T. Chattha, Q. H. Abbasi, "Compact Polarization Diversity Antenna for 28/38 GHz Bands", 18th Int. Symp. Antenna Technol. Appl. Electromagn, 2018.
[13] H. M. Marzouk, M. I. Ahmed, A. A. Shaalan, "A Novel Dual-band 28/38 GHz Slotted Microstip MIMO Antenna for 5G Mobile Applications", IEEE Int. Symp. Antennas Propag. Usn. Radio Sci. Meet., 607-608, 2019

[14] P. Moukala Mpele, F. Mbango, D. Konditi, "A Small Dual Band (28/38 GHz) Elliptical Antenna For 5G Applications with DGS", IJSRT, 2019

[15] C. Balanis, Antenna theory : analysis and design, 1982.

[16] D. M. Pozar, Microwave engineering, Fourth edition, Hoboken, NJ : Wiley, 2012 